\title{
Brain Metastasis from Prostate Small Cell Carcinoma: Not to be Neglected
}

\author{
Corrie E. Erasmus, Wim I.M. Verhagen, Carla A.P. Wauters, Erik J. van Lindert
}

\begin{abstract}
Background: Symptomatic brain metastases from prostatic carcinoma are rare $(0.05 \%$ to $0.5 \%)$. Case report: A 70 -year-old man presented with a homonymous hemianopsia due to brain metastatic prostatic carcinoma shortly before becoming symptomatic of prostatic disease. CT and MRI of the brain showed a tumour deep in the right hemisphere near the thalamus and involving the optic radiation. Results: Routine haematological and biochemical tests were normal. The prostate specific antigen level was low on two separate occasions. The prostatic and brain tumours showed identical appearances, namely of a poorly differentiated adenocarcinoma with neuroendocrine differentiation (small cell carcinoma). Conclusion: A literature review suggests that small cell carcinoma of the prostate is more likely to spread to the brain compared to adenocarcinoma and that brain metastases indicate a poor prognosis. The prostate gland should be remembered as a possible cause of brain metastases and that a normal serum prostate specific antigen does not exclude this diagnosis.
\end{abstract}

RÉSUMÉ: Métastases cérébrales du carcinome à petites cellules de la prostate: une pathologie qui mérite l'attention. Introduction: Les métastases cérébrales symptomatiques d'un carcinome de la prostate sont rares (0,05\% à 0,5\%). Présentation de cas: Un homme âgé de 70 ans a consulté pour une hémianopsie homonyme due à un carcinome prostatique ayant métastasié au cerveau, peu avant de présenter des symptômes de sa pathologie de la prostate. La tomodensitométrie et l'imagerie par résonance magnétique du cerveau ont montré une tumeur située profondément dans l'hémisphère droit près du thalamus et impliquant la radiation optique. Résultats: Les épreuves hématologiques et biochimiques de routine étaient normales. Le taux de l'antigène prostatique spécifique (APS) mesuré à deux reprises était bas. Les tumeurs prostatique et cérébrale avaient une apparence identique, soit celle d'un adénocarcinome peu différencié comportant une différenciation neuroendocrinienne (carcinome à petites cellules, CPC). Conclusion: Une revue de la littérature suggère que le CPC de la prostate est plus susceptible de métastasier au cerveau que l'adénocarcinome, et que des métastases cérébrales indiquent un pronostic défavorable. On devrait penser à la prostate comme site possible d'origine de métastases cérébrales et un APS normal n'exclut pas ce diagnostic.

Can. J. Neurol. Sci. 2002; 29: 375-377

Prostate and lung carcinoma have the highest incidence in males over the age of 50 years. Intracranial metastases from prostate carcinoma are rare and most often diagnosed at autopsy. In a review of 4,421 patients with prostate carcinoma, Lynes et $\mathrm{al}^{1}$ found eight patients with brain metastases; only two were symptomatic, the remaining patients were diagnosed at autopsy. We describe a patient with a symptomatic brain metastasis, that proved to be a metastasis of a mixed prostatic carcinoma and we provide a review of the literature.

\section{CASE RePORT}

A 70-year-old man without significant previous medical history consulted an ophthalmologist because of diminished vision on the left. Clinical examination revealed a left homonymous hemianopsia. Brain CT scan and MRI showed a contrast-enhanced tumour in the right optic radiation (Figure 1). Shortly after the patient developed prostatism owing to a unilaterally enlarged prostate. The prostate specific antigen (PSA) level was normal on two different occasions (1.0 and $1.8 \mu \mathrm{g} / \mathrm{l}$ : normal range $0.0-6.5 \mu \mathrm{g} / \mathrm{l})$.

A prostate biopsy revealed a poorly differentiated adenocarcinoma (Gleason grade $5+5$, stage T3a, advanced disease). ${ }^{2}$ Hormonal therapy (cyproteronacetate) was started. Two months after the radiological diagnosis of the brain tumour, a right temporal craniotomy was

From the Department of Neurosurgery (CEE, EJvL), Neurology (CEE, WIMV) and Pathology (CAPW), Canisius Wilhelmina Hospital, Nijmegen, The Netherlands. ReCEIVED November 16, 2001. ACCEPTED IN FINAL FORM July 9, 2002. Reprint requests to: Wim IM Verhagen, Canisius Wilhelmina Hospital, Department of Neurology, PO Box 9015, 6500GS Nijmegen, The Netherlands 


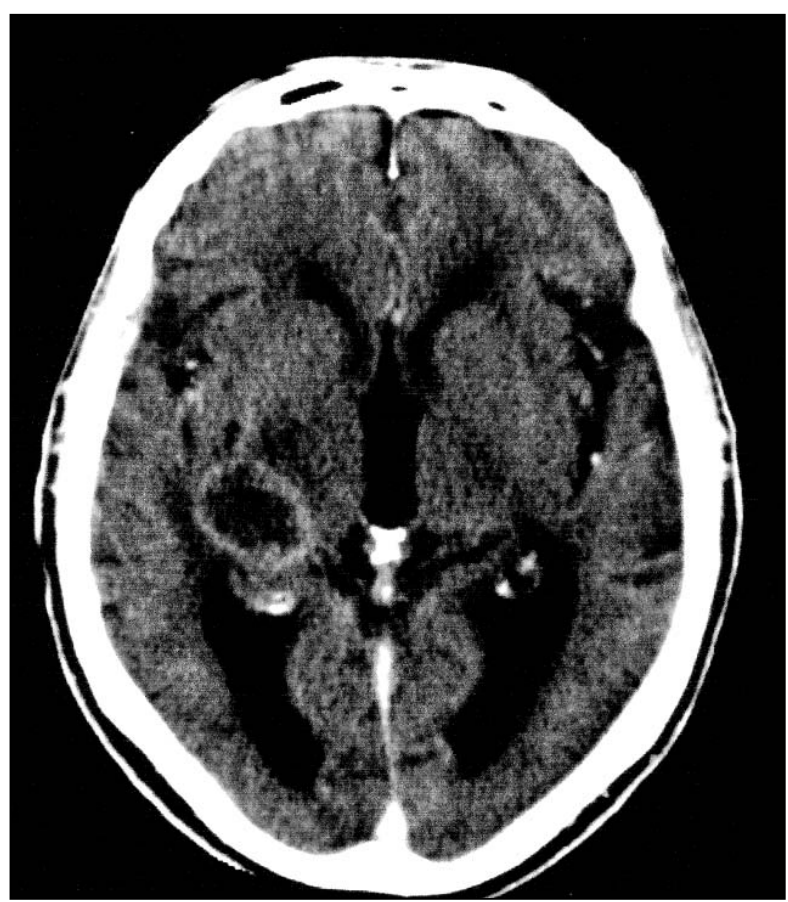

Figure 1: Brain CT-scan shows a contrast-enhancing lesion near the right thalamus.

performed and a subtotal resection of the partly cystic tumour carried out. Salient negative investigations at the time of neurosurgery included routine haematological and biochemical tests and a chest X-ray.

Histological examination of the tumour (Figure 2) showed a poorly differentiated carcinoma with morphology similar to that of the prostate tumour. Prostate specific antigen staining of the brain tumour was negative, whereas the prostate tumour showed only very limited PSA staining. Chromogranine staining was negative in the brain tumour but the recently introduced immunohistochemical neuro-endocrine marker CD56 (NCAM) was positive in the prostate tumour as well as the brain metastasis. From these results we conclude that it must be a poorly differentiated carcinoma with neuro-endocrine differentiation (small cell carcinoma, SCC). CD56 (NCAM) is overexpressed in SCC of the lung and the prostate. ${ }^{3}$ The patient received radiation therapy, 20 Gy in 5 fractions and a booster dose ( $15 \mathrm{~Gy}$ ) in 5 fractions on the intracranial tumour rest. Four months after surgery he died due to metastatic disease with metastases in lymph nodes, bones, liver and lungs. The serum PSA level had always been normal. Autopsy was not performed.

\section{Discussion}

For prostate carcinoma the most common sites of metastases are the bones $(58 \%)$ and the lungs $(32 \%) .{ }^{4}$ Prostate carcinoma disseminates frequently to the spine, but less to the skull. According to Lynes et $\mathrm{al}^{1}$ in their review of the literature, the leptomeninges are the most common site of intracranial involvement of prostate carcinoma. The dura serves as a barrier and therefore subdural and parenchymal metastases from prostate carcinoma have been diagnosed infrequently. Brain

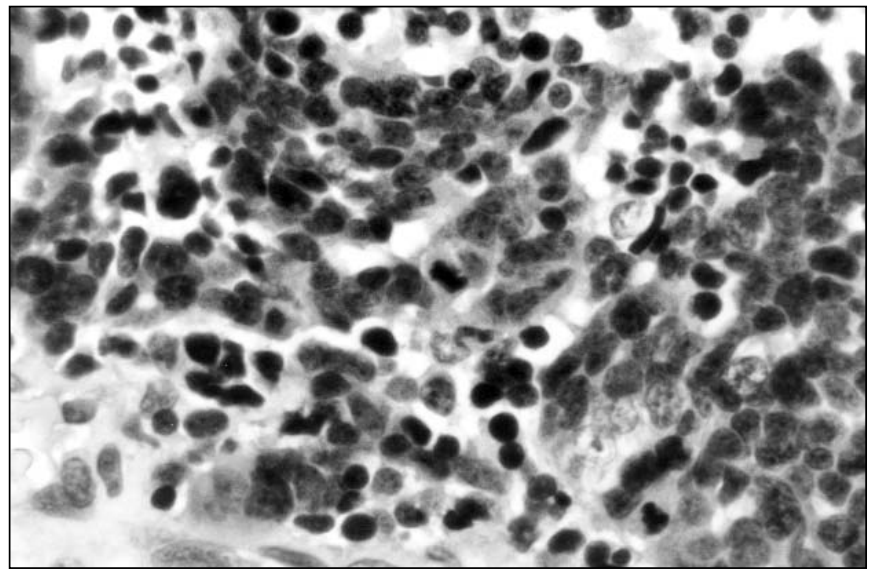

Figure 2: The tumour cells are hyperchromatic and show some moulding. Glands are absent. (hematoxylin \& eosin, magnification $400 x)$.

metastases appeared late in prostate carcinoma. McCutcheon et $\mathrm{al}^{4}$ found a mean of 28.5 months after diagnosing the primary tumour to develop brain metastases. In 6,107 patients with prostate carcinoma, Sutton et $\mathrm{al}^{5}$ found parenchymal brain metastasis in 55 patients of which only 36 were diagnosed during life. Others mentioned a prevalence of brain metastases between 0.7 and $4.4 \%$ at autopsy. ${ }^{1,4,6-8}$ At autopsy in patients with primary SCC of the prostate, McCutcheon et $\mathrm{al}^{4}$ found $9 \%$ brain metastasis. Antemortem diagnosis of prostate carcinoma brain metastases varied between 0.05 and $0.5 \% .^{1,4,6,7}$ Sometimes the patient presents with a brain metastasis prior to recognition of the prostate tumour, as in our patient. In a recent review, Fervenza et $\mathrm{al}^{9}$ mentioned 15 cases. As far as we know, only four patients with antemortem diagnosed SCC metastasis to the brain have been described. ${ }^{10-13}$

Small cell carcinoma of the prostate seems to have a greater tendency to produce brain metastases compared to the adenocarcinoma. ${ }^{4}$ Small cell carcinoma is a rare and very aggressive tumour, with a tendency to disseminate rapidly to soft tissues (lung, liver, lymph nodes), clinically similar to small cell lung carcinoma. Schwartz et $\mathrm{al}^{14}$ mentioned that SCC of the lung, although uncommon, can metastastasize to the prostate, but primary SCC of the prostate may coexist with adenocarcinoma of the prostate, whereas metastatic SCC of the lung does not. Lynes et $\mathrm{al}^{1}$ noted that patients with prostate cancer and brain metastases were younger (mean 59 years) than patients without (mean 70 years).

Patients with known prostatic carcinoma, who survive a long time, are prone to develop a second primary tumour (often lung). If they develop brain metastases, typically they do so as a result of the latter entity. The second primary tumour has a much higher incidence of metastases to the brain. Many prostate carcinomas are quite indolent. ${ }^{4}$ Therefore, we believe that biopsy is necessary for diagnosing the etiology of a brain metastasis even when the patient is known to have prostate carcinoma. The finding of a brain metastasis from prostate carcinoma is relevant for the prognosis. McCutcheon et $\mathrm{al}^{4}$ found a mean survival after 
diagnosing brain metastases of 9.2 months, Chung and Thannikkary ${ }^{7}$ reported 9.5 months.

About $2 \%$ of patients with untreated prostate carcinoma with a metastasis have PSA levels within normal limits. ${ }^{15-18}$ Aihara et $\mathrm{al}^{19}$ mentioned that in Gleason grade 5 tumours, nearly half of the cells showed no PSA staining at all. Negative or weakly positive PSA staining was seen in $90 \%$ of Gleason grade 5 tumours. Serum PSA level is inversely proportional to the degree of tumour differentiation. Serum PSA levels per $\mathrm{cm}^{3}$ tumour decreased with increasing grade. ${ }^{19,20}$ Although PSA level in patients with SCC of the prostate is generally low, there are several reports mentioning elevated PSA levels. ${ }^{14,21,22}$ This may be due to the fact that mixed tumours with SCC and adenocarcinoma are not uncommon. ${ }^{23}$ The relative proportion of each of these types explains the different PSA serum levels. ${ }^{14}$

The absence of PSA staining in the brain tumour of our patient might be due to a response to the hormonal therapy in line with data from Hashine et al. ${ }^{22}$ They found an elevated serum PSA that became normal after endocrine therapy in a case of mixed SCC and poorly differentiated adenocarcinoma of the prostate.

In summary, the prostate should neither be neglected as a source of brain metastasis in patients with prostate cancer, nor in patients without known prostate cancer. A normal PSA level does not exclude prostate cancer irrespective of the presence of metastasis. Small cell carcinoma of the prostate is more likely to produce brain metastasis than the adenocarcinoma but mixed tumours can occur. The SCC component in mixed tumours is responsible for the bad prognosis. A metastatic SCC is usually from the lung, where the primary site may be small, but with a normal chest X-ray and bronchoscopy and as this case shows, other sites, including the prostate, should be considered.

\section{ACKNOWLEDGEMENTS}

The authors thank J. Meijer, radiologist, for providing the neuroimaging data and to J. Meulstee, neurologist, for his comments.

\section{REFERENCES}

1. Lynes WL, Bostwick DG, Freiha FS, Stamey TA. Parenchymal brain metastases from adenocarcinoma of prostate. Urology 1986; 28:280-287.

2. Gleason DF. Histologic grading and clinical staging of prostatic carcinoma. In: Tannenbaum M, (Ed.) Urologic pathology: the prostate. Philadelphia: Lea \& Febiger, 1977:171-198.

3. Lynch DF, Hassen W, Clements MA, Schellhammer PF, Wright GL. Serum levels of endothelial and neural cell adhesion molecules in prostate cancer. Prostate 1997;32:214-220.

4. McCutcheon IE, Eng DY, Logothetis CJ. Brain metastasis from prostate carcinoma. Antemortem recognition and outcome after treatment. Cancer 1999; 86:2301-2311.

5. Sutton MA, Watkins HL, Green LK, Kadmon D. Intracranial metastases as the first manifestation of prostate cancer. Urology 1996; 48:789-793.

6. Catane R, Kaufman J, West C, et al. Brain metastasis from prostatic carcinoma. Cancer 1976; 38:2583-2587.

7. Chung TS, Thannikkary C. Carcinoma of the prostate with brain metastasis. J Surg Oncol 1986; 33:103-105.

8. Saitoh H, Hida M, Shimbo T, et al. Metastatic patterns of prostatic cancer. Correlation between sites and number of organs involved. Cancer 1984; 54:3078-3084.

9. Fervenza F, Wolanskyj AP, Eklund HE, Richardson RL. Brain metastasis: an unusual complication from prostatic adenocarcinoma. Mayo Clin Proc 2000; 75:79-82.

10. Freedy RM, Miller KD Jr. Small cell carcinoma of prostate: metastases to the brain as shown by CT and MRI with pathologic correlation. AJNR 1990;11:947-948.

11. Blunt DM, Sansom HE, King DM. Imaging of small cell carcinoma of the male urogenital tract. Clin Radiol 1996;51:724-727.

12. Rivas Alonso A, Gomez Dorronsoro M, Valenti Ponsa C. Carcinoma de celula pequena de prostata con metastasis cerebral. Actas Urol Esp 1996;20:582-585.

13. Zachariah B, Casey L, Zachariah SB, Baekey P, Greenberg HM. Case report: brain metastasis from primary small cell carcinoma of the prostate. Am J Med Sci 1994; 308:177-179.

14. Schwartz LH, LaTrenta LR, Bonaccio E, et al. Small cell and anaplastic prostate cancer; correlation between CT findings and prostate-specific antigen level. Radiology 1998;208:735-738.

15. Ercole CJ, Lange PH, Mathisen M, et al. Prostate specific antigen and prostatic acid phosphatase in monitoring and staging of patients with prostatic cancer. J Urol 1987; 138:1181-1184.

16. Leo ME, Bilhartz DL, Bergstralh EJ, Oesterling JE. Prostate specific antigen in hormonally treated stage D2 prostate cancer: is it always an accurate indicator of disease status? J Urol 1991; 145:802-806.

17. Smith JA Jr, Crawford ED, Lange PH, et al. PSA correlation with response and survival in advanced carcinoma of the prostate. J Urol 1991; 145:384a.

18. Leibman BD, Dillioglugil O, Wheeler TM, Scardino PT. Distant metastasis after radical prostatectomy in patients without an elevated serum prostate specific antigen level. Cancer 1995; 76:2530-2534

19. Aihara M, Lebovitz RM, Wheeler TM, et al. Prostate specific antigen and Gleason grade: an immunohistochemical study of prostate cancer. J Urol 1994; 151:1558-1564.

20. Partin AW, Carter HB, Chan DW, et al. Prostate specific antigen in staging of localized prostate cancer: influence of tumour differentiation, tumour volume and benign hyperplasia. J Urol 1990;143:747-752.

21. Aygun C. Small cell carcinoma of the prostate: a case report and review of the literature. Md Med J 1997; 46:353-356.

22. Hashine K, Nakatsuji H, Karashima T, et al. Small cell carcinoma of the prostate: a case report. Hinyokika Kiyo 1998;44:607-610.

23. Rubenstein JH, Katin MJ, Mangano MM, et al. Small cell anaplastic carcinoma of the prostate: seven new cases, review of the literature, and discussion of a therapeutic strategy. Am J Clin Oncol 1997;20:376-380. 